\title{
Therapy in type 2 diabetes: A logical empiricism - based approach
}

\author{
Sanjay Kalra, Yashdeep Gupta ${ }^{1}$ \\ Department of Endocrinology, Bharti Hospital and BRIDE, Karnal, ${ }^{1}$ Department of Medicine, Government Medical College, Chandigarh, \\ Haryana, India
}

\section{A B S T R A C T}

There is ongoing debate about the relevance of the "guideline approach," vis-a-vis the "pathophysiologic approach" in the management of diabetes. However, it is disheartening to note that both these stands neglects the most important people involved in diabetes management: The person with diabetes, the family, and the treating physician. We discuss a logical empiricism based approach for diabetes care in this brief communication.

Key words: Guidelines, insulin, oral hypoglycemic agents

\section{INTRODUCTION}

Ongoing debate about the relevance of the "guideline approach," vis-a-vis the "pathophysiologic approach" may never cease. ${ }^{[1,2]}$ However, it is disheartening to note that both these stands neglect the most important people involved in diabetes management: The person with diabetes, the family, and the treating physician. ${ }^{[3]}$

\section{The person with diabetes}

Each person with diabetes is unique, with an individual personality and background. These personal characteristics modulate his or her response to the diagnosis of diabetes, including coping mechanisms, healthcare-seeking behavior, healthcare utilization patterns, and healthcare acceptance. This individual makeup can never be described adequately in terms of beta cell function, insulin resistance, and other, newer facets of metabolic dysfunction.

\begin{tabular}{|l|l|}
\hline \multicolumn{2}{|c|}{ Access this article online } \\
\hline Quick Response Code: & Website: \\
\hline & www.josh.net \\
\hline & \\
\hline & \\
\hline
\end{tabular}

The bio-psychosocial model of health perhaps, is a more appropriate framework, through which a person with diabetes can be approached and assessed. The biopsychosocial model encompasses not only currently highlighted biological or biochemical variables but also focuses attention on other equally important aspects of health. ${ }^{[4,5]}$

Individual attitudes towards disease: The perceived severity of illness, the perceived efficacy and safety of drug therapy, the ability and willingness to make necessary change in lifestyle, to accept injectable therapy, and to selfmonitor blood glucose at optimal frequency, are equally important in diabetes praxis. The locus of control, whether external or internal, and ability to communicate with the healthcare provider also affects initial response to the diagnosis of diabetes.

\section{The healthcare system}

Practical concerns, including availability, accessibility, and affordability of health care, specifically diabetes care, play an important role in deciding management. These may differ from person to person. The relative availability, accessibility, and affordability of various components of diabetes care may vary in different healthcare settings. Some relatively less developed 'pay from pocket' markets, for example, may allow unhindered access to diabetes specialists, at low costs, but place a high premium on newer anti-diabetic drugs. Other 'advanced' nations may 
facilitate availability of the latest molecules for diabetes therapy, but restrict access to specialists through longwaiting lists. Again, some healthcare settings may offer cheap, easily accessible point of care testing, even though glucometers for self-monitoring may be expensive. Other health care systems may provide glucometers and ancillary supplies free of cost to people with diabetes but regulate or discourage contact with laboratory technicians. This is unfortunate because these paramedical staff can also be a vehicle for diabetes education. Some healthcare settings may offer structured diabetes education courses, while in others, education and counseling is integrated into routine medical care visits.

\section{The family and society}

The social environment of the person with diabetes, i.e., his or her family and community impacts choice of therapy. ${ }^{[6]}$ Examples of 'social modulation' include motivation to try complementary and alternative medicines, to practice doctor-shopping, and to incorporate lifestyle modification.

\section{The physician}

Apart from these factors, the treating physician too needs mention as factor in choosing therapy for diabetes. Education, practical training, experience, with various classes of drugs, exposure to currently guidelines and developments, and peer opinion all serve to modulate prescription habits. Sulfonylureas may be safe in the hands of a physician trained and experienced in their judicious use. This may be even safer if the physician practices patient empowerment to the extent of explaining self-titration of dose to the patient, to be done in cases of hypoglycemia. The same physician, however, may not be skilled at using insulin analogues, perhaps because of lack of practical experience or training.

The cumulative experience and confidence of diabetes care professional in prescribing a particular molecule, or class of drug, is what we term as "physician's metabolic memory." Individual physician metabolic memory as well as "collective physician metabolic memory" (including opinion of peers, colleagues, and seniors) plays an important role in deciding choice of therapy. This fact should not be frowned upon: On the contrary, it should be encouraged. Optimal choice of pharmacotherapy dose not only entails just an appropriate initial prescription, it also includes follow up, pharmaco-vigilance, and careful watch for adverse events. It would be much safer for a person with diabetes to take a drug whose side effects his or her physician is trained to recognize, rather than a scenario where a "safer" drug is prescribed without ability for timely recognition of side effects.

\section{The path of logical empiricism}

To bring the debate to a conclusion, we propose yet another approach, based on logical empiricism. The phrase, logical empiricism, is taken from a school of science philosophy which flourished in the early and mid-twentieth century. A call for the use of logical empiricism has been made earlier in diabetology and in allied specialties as well. ${ }^{[7,8]}$

For a diabetes care professional, logical empiricism conveys exactly what it means: Empirical therapy, based on logic or evidence. The astute diabetes care professional knows the logic or evidence available, but uses it empirically, to suit the individual and socio-economic needs of a person with diabetes, ${ }^{[7]}$ In effect, therefore, logical empiricism become a synonym for person-centered care or individualized/ personalized care.

Logical empiricism is an extension of observation-based medicine or experience-based medicine. Viewing the person with diabetes through a bio-psychosocial prism, the "logically empirical" or" empirically logical" physician aims to craft a therapeutic regime most suited for the particular clinical situation. She or he considers the unique background of the person with diabetes, his or her family, and his or her society while planning therapy.

From a pharmacological point of view, a few drugs which are extensively used in Asia deserve mention here. The role of premixed insulin, alpha glucosidase inhibitors, and sulfonylureas is consistently downplayed by western guidelines. This discrepancy between practice and guidelines should stimulate discussion and debate. Perhaps Asian and African diabetologists prescribe these drugs preferentially, because of a "collective positive metabolic memory," encouraged by positive therapeutic benefits noted in patients. In other words, they practice a form of informal logical empiricism [empirical therapy, based upon logic]? Perhaps western guideline-writers labor under their own metabolic memory. Their guidelines are influenced by locally generated evidence, which may be appropriate for their particular clinical scenario but not for others. Either way, more introspection and more action is necessary.

\section{REFERENCES}

1. Raz I. Guideline approach to therapy in patients with newly diagnosed type 2 diabetes. Diabetes Care 2013;36( Suppl 2): S139-44.

2. DeFronzo RA, Eldor R, Abdul-Ghani M. Pathophysiologic approach to therapy in patients with newly diagnosed type 2 diabetes. Diabetes Care 2013;36(Suppl 2):S127-38.

3. Kalra S, Megallaa MH, Jawad F. Patient-centered care in diabetology: From eminence-based, to evidence-based, 
to end user-based medicine. Indian $\mathrm{J}$ Endocrinol Metab 2012;16:871-2.

4. Kalra S, Balhara YP, Das AK. The bio-psycho-social model and the American Diabetes Association European Association for the study of diabetes position statement on management of hyperglycemia. J Soc Health Diabetes 2013;1:53-5.

5. Engel GL. The need for a new medical model: A challenge for biomedicine. Science 1977;196:129-36.

6. Kalra S, Megallaa MH, Jawad F. Perspectives on patient-centered care in diabetology. J Midlife Health 2012;3:93-6.
7. Kalra S. Logical empiricism and diabetes management. Int J Clin Cases Investig 2012;4:1-2.

8. Bajwa SJ, Kalra S. Logical empiricism in anesthesia: A step forward in modern day clinical practice. J Anaesthesiol Clin Pharmacol 2013;29:160-1.

How to cite this article: Kalra S, Gupta Y. Therapy in type 2 diabetes: A logical empiricism - based approach. J Soc Health Diabetes 2014;2:109-11.

Source of Support: Nil, Conflict of Interest: None declared. 